\title{
Structural design and construction of an office building with laminated bamboo lumber
}

\author{
Jingwen Su ${ }^{\text {a }}$, Haitao Li $^{\text {b, }{ }^{*} \text {, Zhenhua Xiong }}{ }^{\text {d, b }}$, Rodolfo Lorenzo ${ }^{\text {e }}$ \\ a Nanjing Technical Vocational College, Nanjing 210019, China. \\ ${ }^{\mathrm{b}}$ Joint International Research Laboratory of Bio-composite Building Materials and Structures, Nanjing Forestry University, \\ Nanjing 210037, China \\ ${ }^{\mathrm{c}}$ College of Civil Engineering, Nanjing Forestry University, Nanjing 210037, China. \\ ${ }^{\mathrm{d}}$ Ganzhou Sentai bamboo company LTD, Ganzhou 341001, China \\ ${ }^{e}$ University College London, London WC1E 6BT, UK. \\ *Corresponding Author: Haitao Li, Professor; E-mail: 1haitao1982@126.com
}

\begin{abstract}
With so many advantages such as environmental friendliness, fastgrowing, high strength-to-weight ratio, sustainability, and the capability of being reused or recycled, bamboo structures has gained more and more attention for scientists. This paper shows the feasibility of the design of an office building using laminated bamboo lumbers in compliance with the Chinese standards as GB50009-2012, GB50011-2010, GB50016-2014, and GB 50005-2017. Detailed information about the materials and building were offered. A lot of related construction photos were offered to show the building process. This case is a very good application example for laminated bamboo lumber buildings and has attracted many engineers' attention in industrial field. Laminated bamboo lumber structures should have a bright future. It should become one main structure form in civil engineering area. However, due to none existing engineered bamboo structures design standard now, engineers have to take reference to standards for timber structures. Setting up the standard system is very important for engineered bamboo structures' application. Through more and more scientists' hard working, it might be not a long way to build the code system.
\end{abstract}

Keywords: Laminated bamboo lumber; office building; design; construction

\section{Introduction}

As known by everyone, mineral resources for constructions are limit in our globe. That is why more and more scientists are paying attention to the bio-resources [1-28]. Bamboo and wood are natural green building materials [1-5]. They have many advantages such as environmental friendliness, sustainability, and the capability of being reused or recycled [5-8]. While it takes shorter harvesting period for bamboo than that for wood. Just 3-5 years from the time of planting is needed for bamboo [9-15]. Besides the above advantages, bamboo also has high efficiency in comparison to other construction materials, and its strength-to-weight ratio is greater than that of common wood, aluminum alloy, cast iron, and steel [15-22].

Due to limit diameter and low rigidity, bamboo can't be used widely in modern buildings. Engineered bamboo materials could solve these problems [1-22]. There are many different kinds of

000010-1

Received: 2 September 2021; Received in revised form: 9 October 2021; Accepted: 14 October 2021 This work is licensed under a Creative Commons Attribution 4.0 International License. 
industrial bamboo products now such as laminated bamboo lumber (LBL), parallel bamboo strand lumber (scrimber bamboo), bamboo winding composite materials, bamboo plastic composite materials, bamboo weave composite materials (glue bamboo), bamboo particle composite materials, bamboo wood composite materials and so on [1-9, 28]. Different products have different characteristics and manufacturing technologies. Laminated bamboo lumber (LBL) is one kinds of main products in the supermarket and has been widely used in construction area [9-28].

After disassembling the natural bamboo tubes into thin flat laminae and some treating procedures, laminated bamboo lumber LBL could be formed by laminating the thin strips together. LBL could solve the problems of size limitation and dimensional consistency, strength, and uniformity [22-28]. There are two main series of LBL products which are parallel laminated bamboo lumber (Fig. 1) [25-28] and cross laminated bamboo lumber (Fig. 2) [25-28].

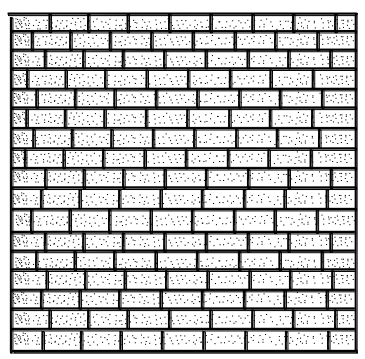

(a) Flat pressure type

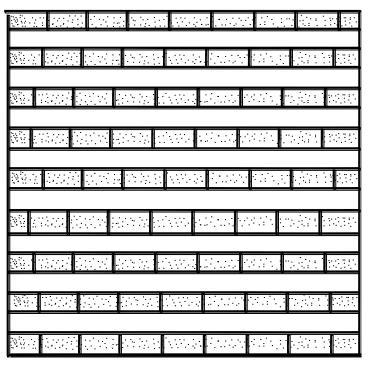

(a) Flat pressure type

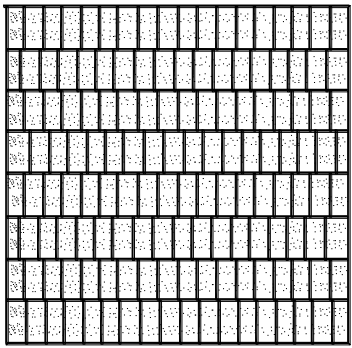

(b) Side pressure type

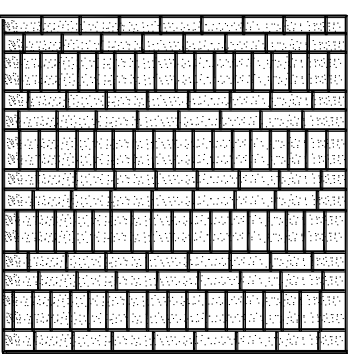

(c) Combined pressure type

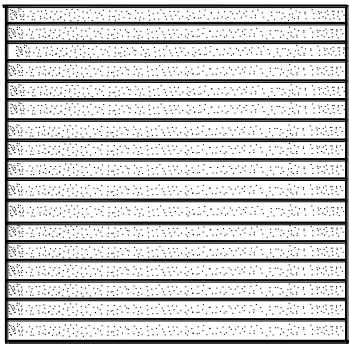

(d) Flattening bamboo type

Fig. 1. Parallel laminated bamboo lumber [2]

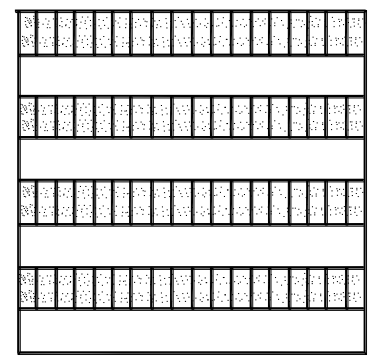

(b) Side pressure type

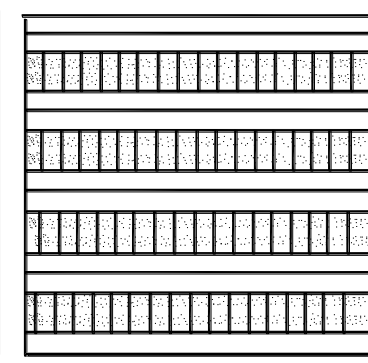

(c) Combined pressure type

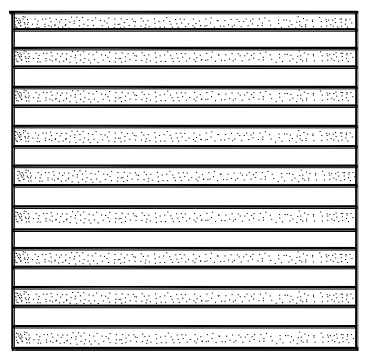

(d) Flattening bamboo type

Fig. 2. Cross laminated bamboo lumber [28]

As one main promising wood substitute, LBL has attracted more and more researchers' attention. A large quantities of studies [9-28] have been carried out about its basic mechanical properties and structural performance. More and more structural applications appeared in construction filed. This paper will introduce one main application example which was started in 2019 and finished in 2020 as an office building.

\section{Materials chosen for the case}

The main manufacturing process for laminated bamboo lumber used in this project were shown in Fig. 3. Harvested at the age of 3-6 years (Fig. 1a), Moso bamboo (Phyllostachys pubescens, from Fujian province) was chosen for LBL. Firstly, original bamboo poles were cut into a length of $2005 \mathrm{~mm}$ and then split into bamboo strips with the width of $22-24 \mathrm{~mm}$ (Fig. 1c). Secondly, both the inner cavity layer (pith peripheral) and the outer skin (epidermal) of the strips were removed (Fig. 1d) by a planer. Then all strips were put in one specific tank for charring to remove the nutrition, sugar and so on (Fig. 1e). After drying and fine planning, the final bamboo strips with the thickness of $7 \mathrm{~mm}$ and width of $21 \mathrm{~mm}$ were obtained for the glue rolling process (Fig. 1f). Phenol glue was chosen here. Side pressure type was chosen for LBL making. The single layers (Fig. 1g) were manufactured firstly and then were put into a tank for durability treatment (Fig. 1h). Finally, all single layers were pressed together to form the big blocks (Fig. 1i).

The basic mechanical properties of LBL have been tested and the main test results could be seen from Table 1. The test mean value for the density of the materials is $0.622 \mathrm{~g} / \mathrm{cm}^{3}$ with the standard 
deviation of $0.019 \mathrm{~g} / \mathrm{cm}^{3}$. It could be seen from the test that LBL has good mechanical characteristics which was also proved by other scientific research.

Table 1. Mechanical properties of LBL [28]

\begin{tabular}{ccccccc}
\hline & $\begin{array}{c}\text { Tensile } \\
\text { parallel to } \\
\text { grain }\end{array}$ & $\begin{array}{c}\text { Tensile } \\
\text { perpendicular to } \\
\text { grain }\end{array}$ & $\begin{array}{c}\text { Compression } \\
\text { parallel to } \\
\text { grain }\end{array}$ & $\begin{array}{c}\text { Compression } \\
\text { perpendicular to } \\
\text { grain }\end{array}$ & $\begin{array}{c}\text { Shear } \\
\text { parallel } \\
\text { to grain }\end{array}$ & Bending \\
\hline $\begin{array}{c}\text { Strength /MPa } \\
\begin{array}{c}\text { Elastic } \\
\text { modulus } / \mathrm{MPa}\end{array}\end{array}$ & 84.5 & 4.15 & 71.6 & 16.5 & 13.9 & 92.6 \\
\hline
\end{tabular}

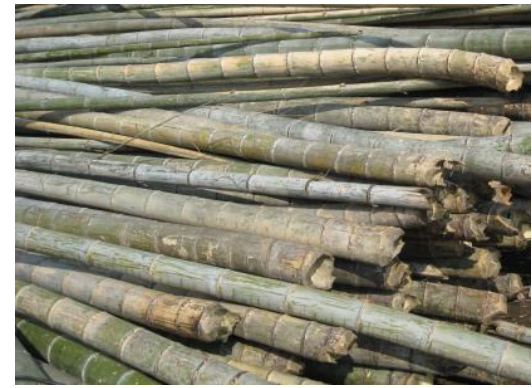

(a) Original bamboo

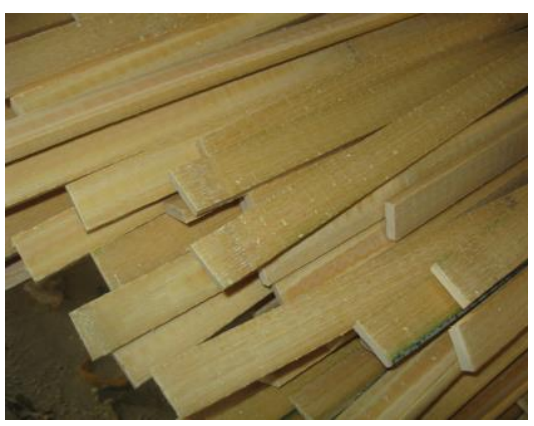

(d) Plane

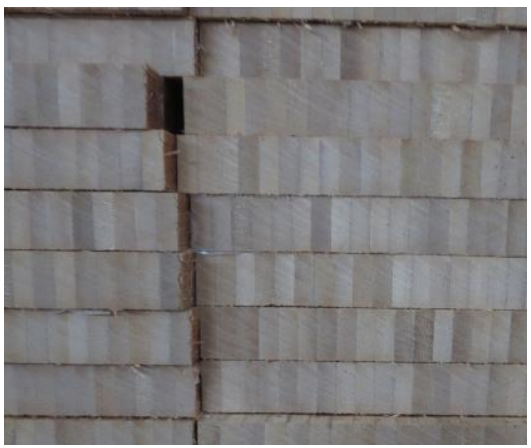

(g) Single layer

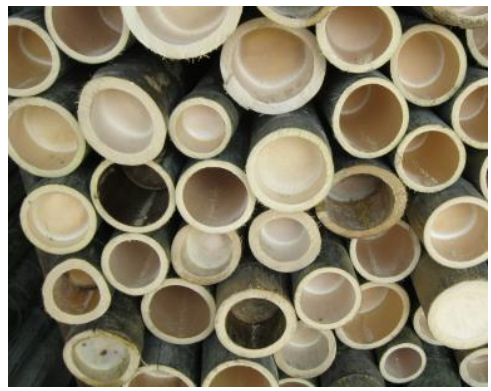

(b) Cut off

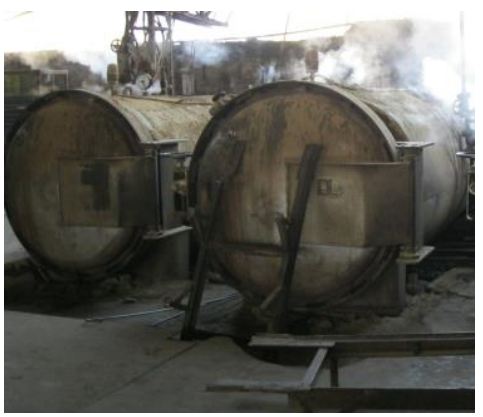

(e) Charring

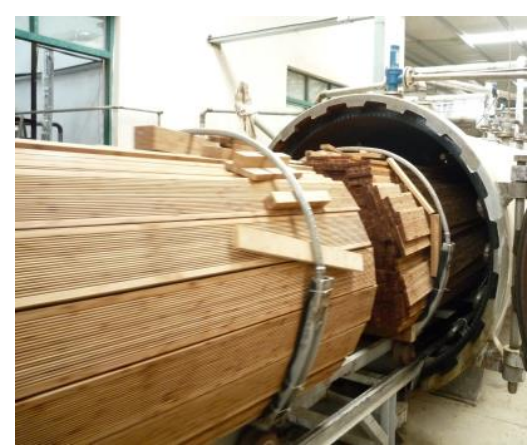

(h) Durability treatment

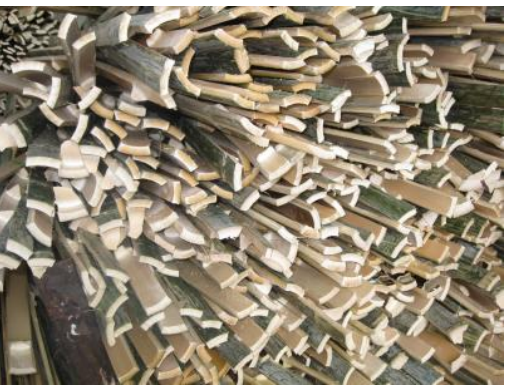

(c) Original bamboo strips

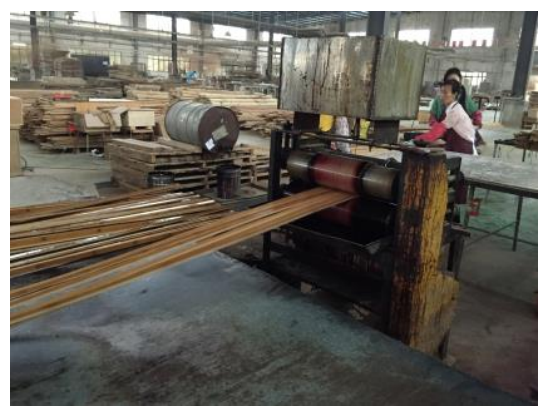

(f) Roll gluing

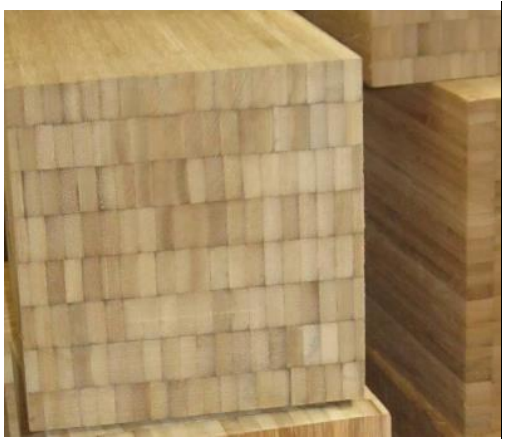

(i) Structural section

Fig. 3. Manufacturing process for LBL

\section{Design of the building}

The case was inspired by a laminated bamboo lumber building designed by Haitao Li's team working with Ganzhou Sentai Bamboo Company LTD and it's mainly used as the company's office building, shown in Fig. 4. The design work for this building was finished in 2018. The structure of the building is a beam-column system. Steel plates and bolts were chosen for the structural connections. The materials used were illustrated in the above and manufactured by Ganzhou Sentai Bamboo Company LTD. With the height of $12800 \mathrm{~mm}$ for the tallest building point, the total building area for 
the case is about 1100 square meters. Concrete foundation combined with bricks was chosen for the building. The space for the ground floor of the building is mainly used for products exhibition and staff canteen. While the second floor is mainly for the staff office and the third floor is a big meeting room. The height for the tallest building point is $12800 \mathrm{~mm}$.

Both the calculations methods by hand and by the finite element software SAP2000 were chosen for structural design of the building. The actions on the building, such as snow, wind and earthquake, the requirements set out in Chinese standards as GB50009-2012 [30], GB50011-2010 [31], GB500162014 [32], and GB 50005-2017 [33] are adopted. As the stiffness for the bolt steel plate connections lies in between the rigid connections and hinge connections, two models of the same structure were considered and calculated. The first one is with rigid constraints in the beams-columns nodes to maximize the stresses in the columns, and the other is with hinges in the connections to maximize the stresses in the beams. The heaviest stresses deriving from these two models were considered for each structural member to be in the most unfavorable possible condition for each member.

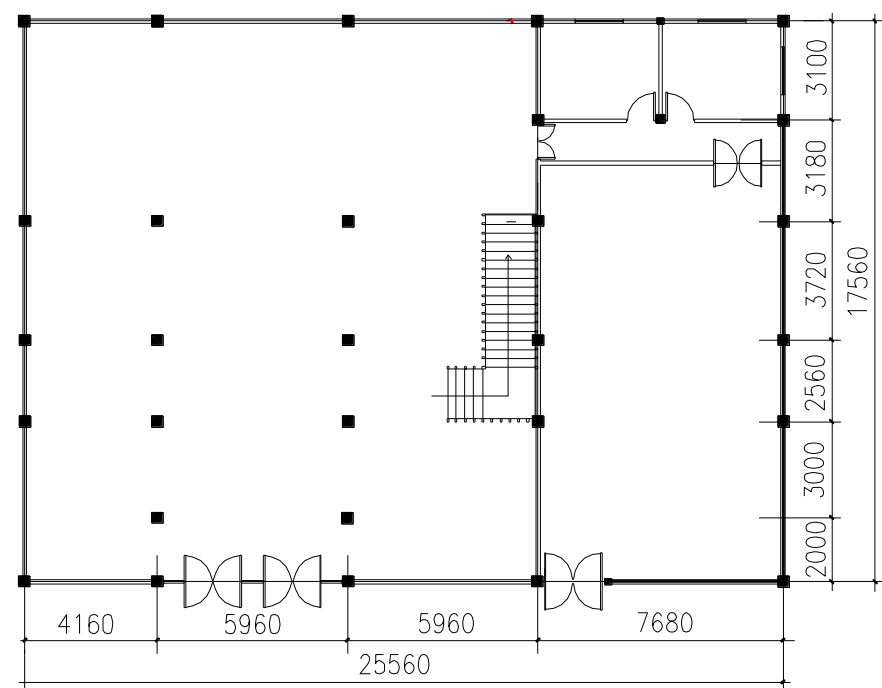

(a) Structural plan of the first floor (unit: $\mathrm{mm}$ )

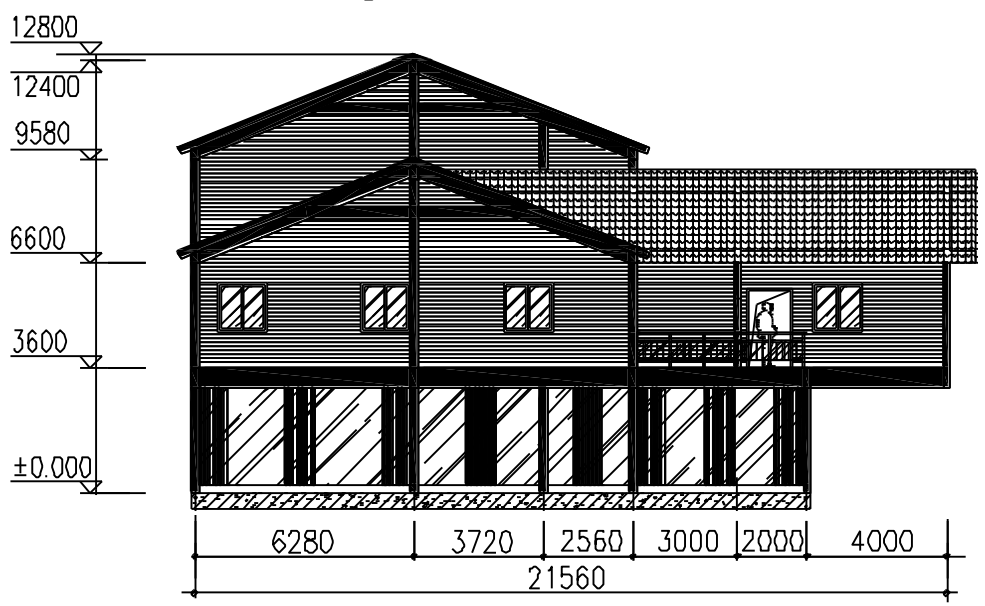

(b) South Elevation (unit: $\mathrm{mm}$ )

Fig. 4. Plan and section of the building

\section{Construction of the building}

The building was set up for two years off and on. The construction work began in 2019. Concrete foundation combined with bricks was finished during this period and most of columns were erected on the foundation by using bolt and steel plate connections meanwhile. Due to many other reasons, all other construction work was finished in Ganzhou in 2020. Carriage hoist played an important role in the construction process. Oriented Strand Boards (OSB) were chosen both for the walls and the roofs. 
Nails were used to connect OSB boards with the structural elements such as the beams or columns. Fig. 5 shows some typical photos for the whole construction process.

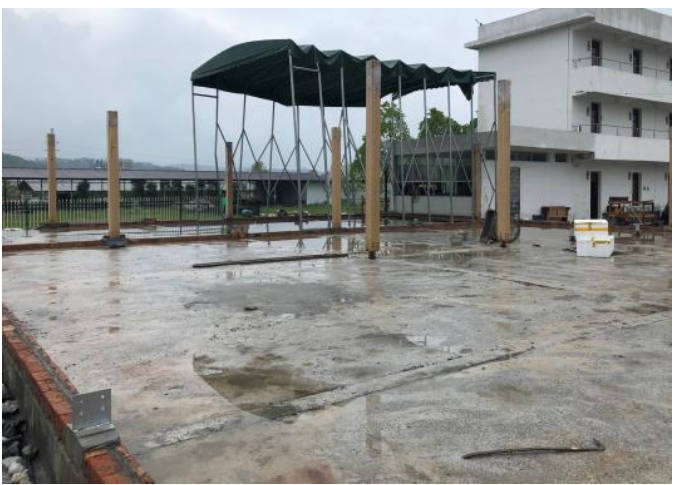

(a) Foundation

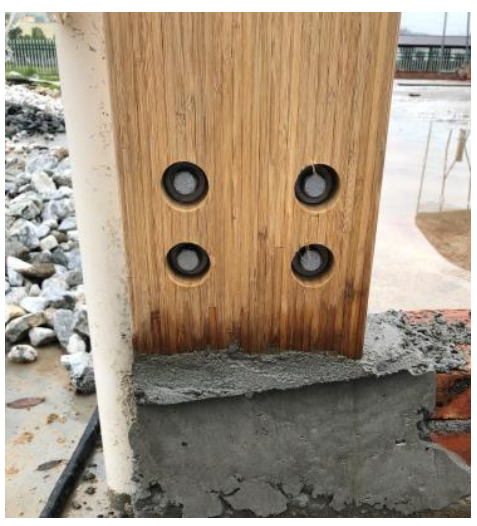

(d) Bolts connection side

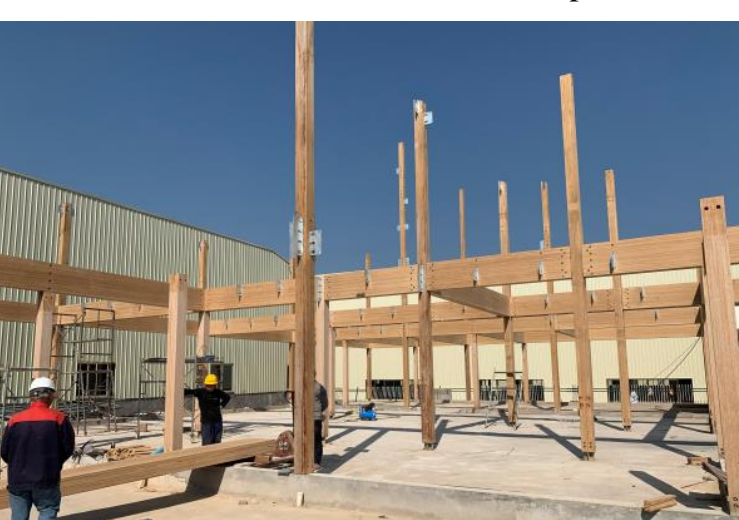

(g) Structural system for the first floor

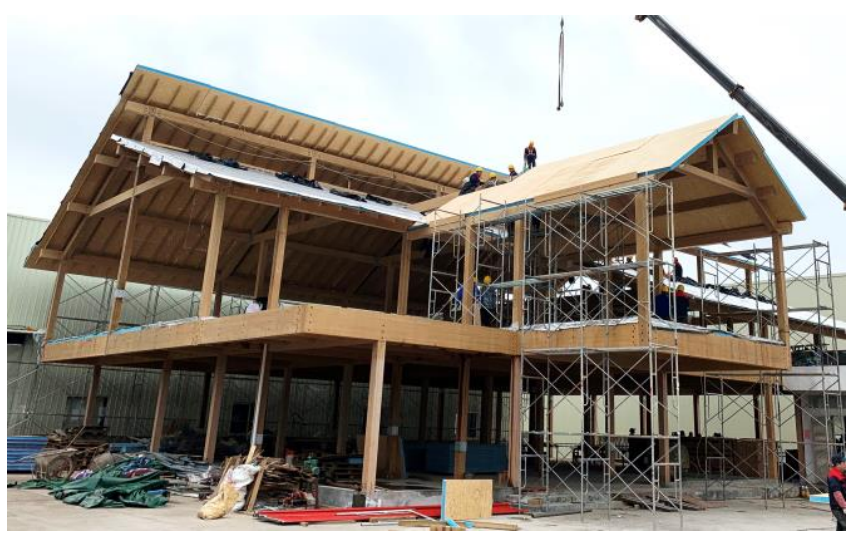

(i) Roof construction

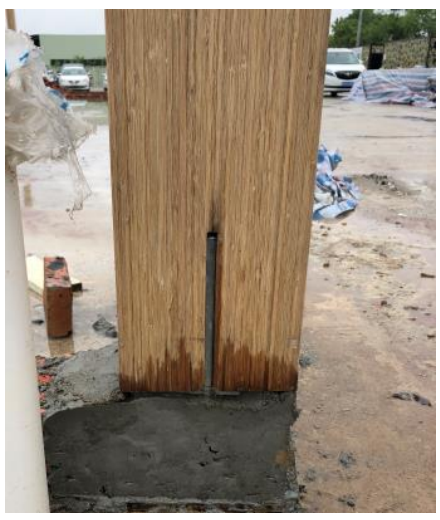

(e) Steel plate connection side

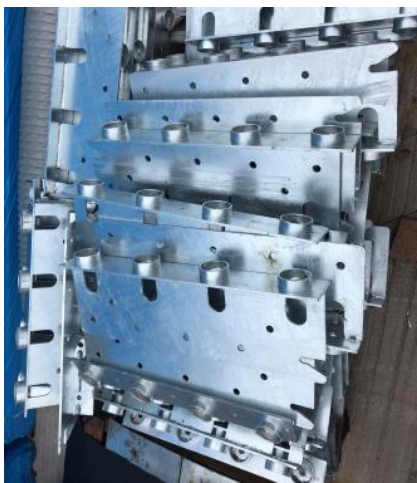

(b) Bolts and steel plates

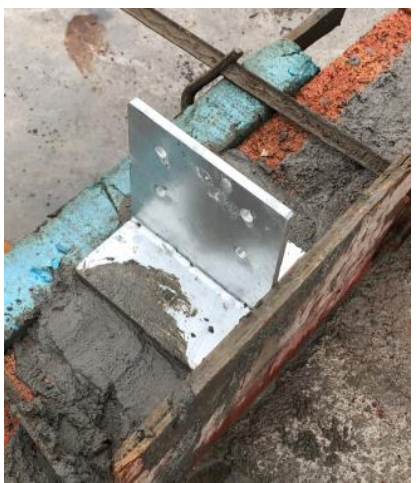

(c) Connection and the base

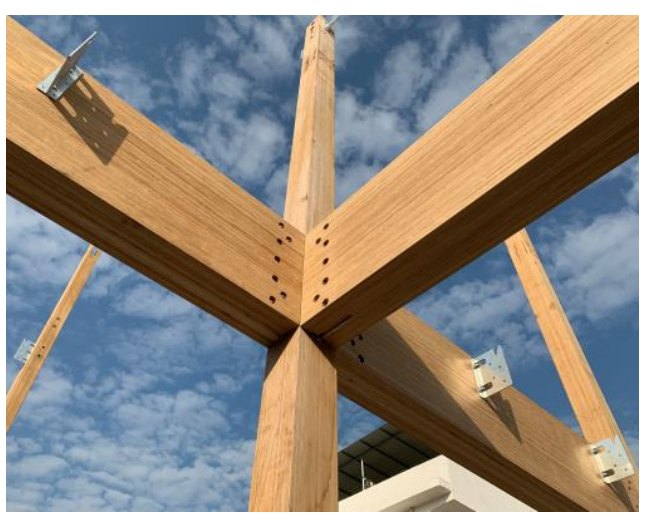

(f) Connections between columns and beams

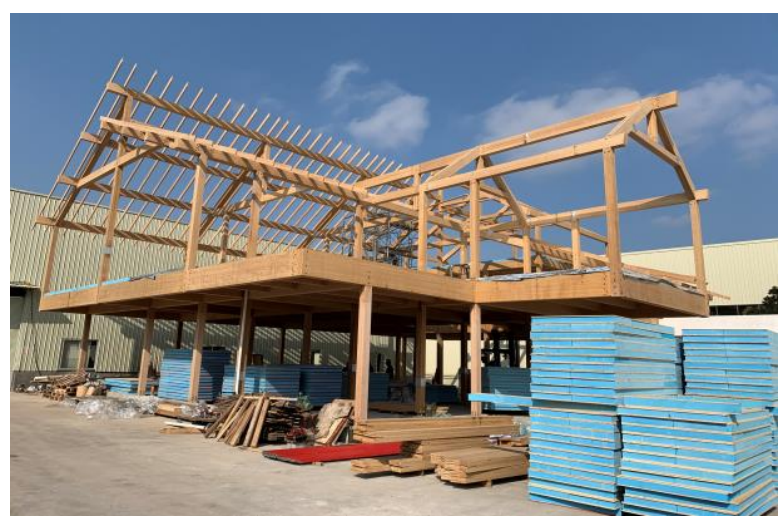

(h) Structural system for the whole building

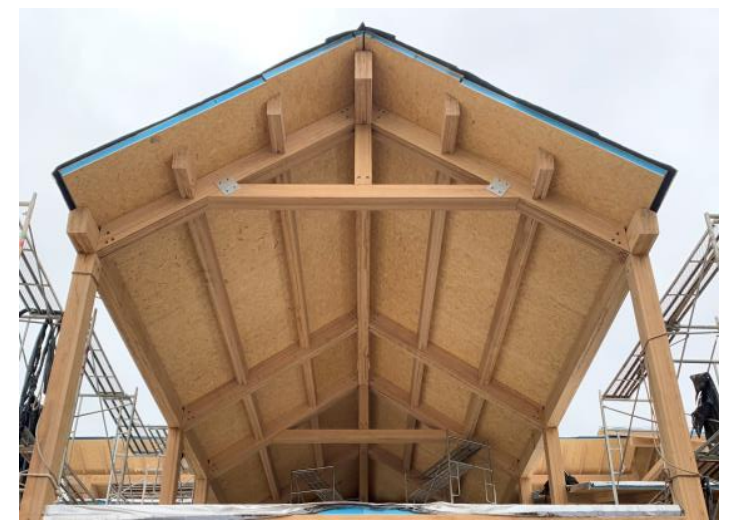

(j) Inner side of the roof 


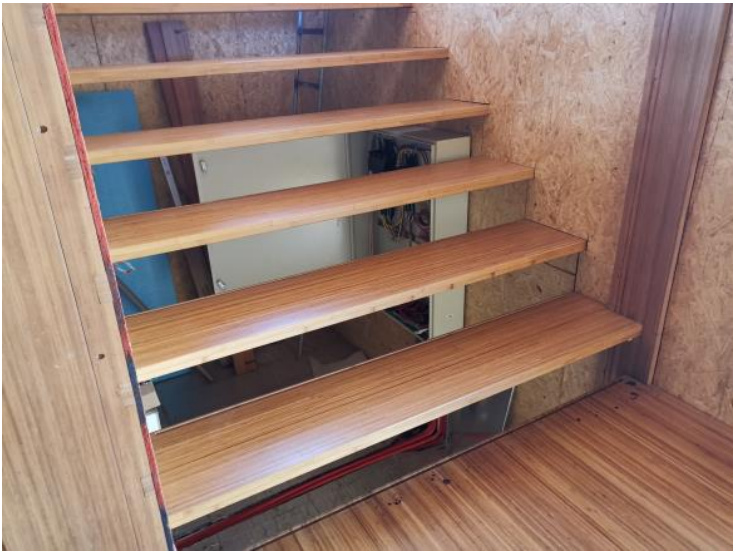

(k) Stairs

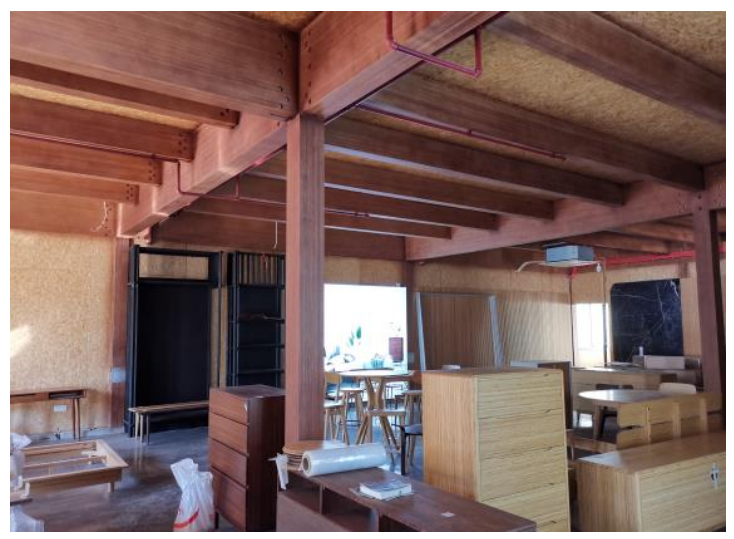

(m) Structural system inside

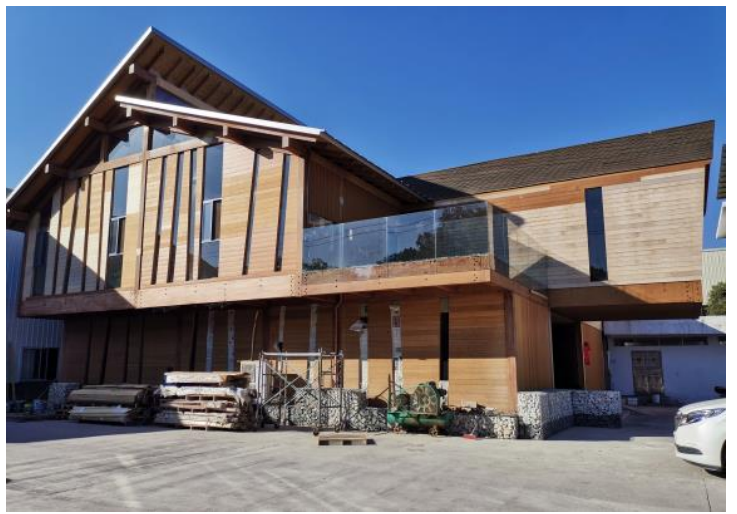

(o) Photo taken from the south

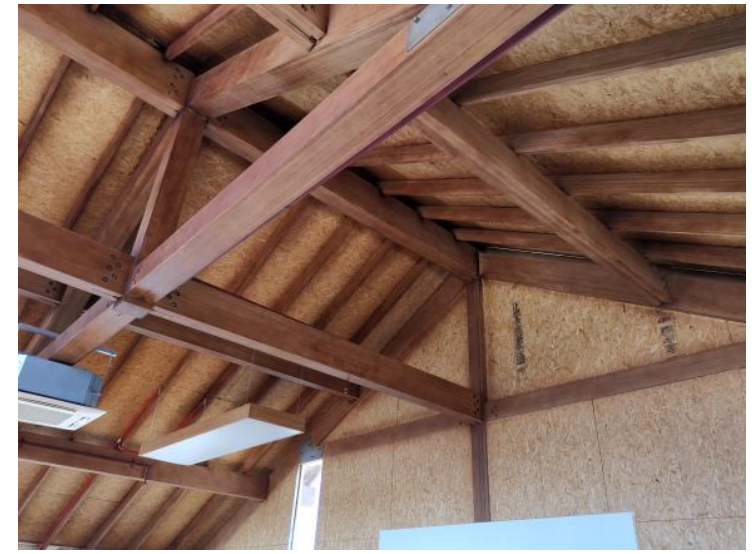

(1) Structural system for the roof

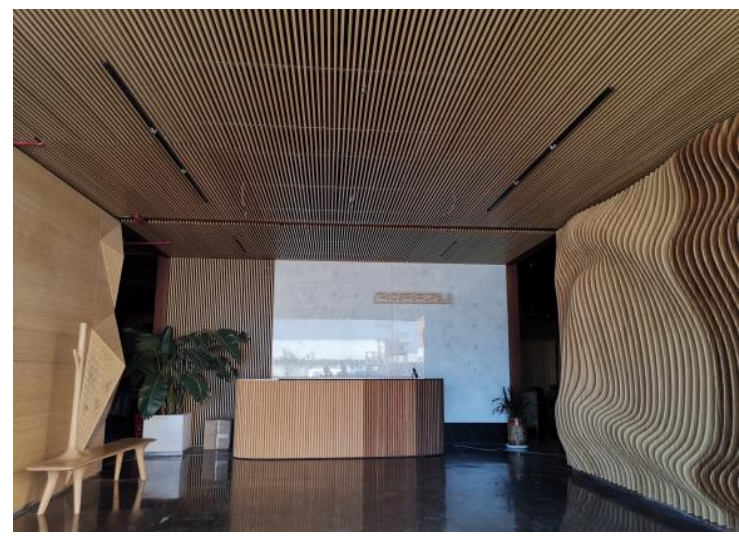

(n) Entrance of the building

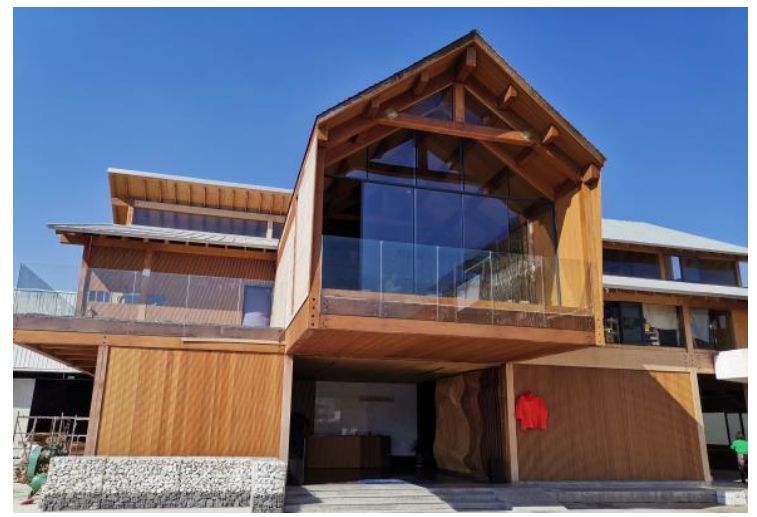

(p) Photo taken from the entrance side

Fig. 5. LBL building construction

\section{Conclusions}

The paper shows the feasibility of the design of an office building using laminated bamboo lumbers in compliance with the Chinese standards as GB50009-2012, GB50011-2010, GB50016-2014, and GB 50005-2017. Detailed information about the materials and building were offered. A lot of related construction photos were offered to show the building process. This case is a very good application example for laminated bamboo lumber buildings and has attracted many engineers' attention in industrial field. With so many advantages such as environmental friendliness, fast-growing, high strength-to-weight ratio, sustainability, and the capability of being reused or recycled, laminated bamboo lumber structures should have a bright future. It should be one main structure form for the future buildings. However, there are still none engineered bamboo structures design standard now. Engineers have to take reference to the standards for timber structures. Setting up the standard system is very important for engineered bamboo structures' application. Through more and more scientists' 
hard working, it might be not a long way to build the code system.

\section{Acknowledgement}

The writers gratefully acknowledge Xiaohong Xiong, Yeqing Xie, Kangwen Wu, Ziwen Yan, Weilai Zhou, Zhen Cao, Zhongjin Han, Rong Liu, Zhenyu Qiu, Huizhong, Zhang, Chaokun Hong, Dong Yang, Xiaoyan Zheng, Shaoyun Zhu, Liqing Liu, Dunben Sun, Jing Cao, Yanjun Liu, Junhong $\mathrm{Xu}$ and others from the Ganzhou Sentai bamboo company LTD and Nanjing Forestry University for assisting in various capacities.

\section{Funding Statement}

This work was supported by the Ministry of Housing and Urban-Rural science project of Jiangsu Province under Grant No. 2021ZD10; the National Natural Science Foundation of China (No. 51878354 \& 51308301); the Natural Science Foundation of Jiangsu Province (No. BK20181402 \& BK20130978). All research outcomes presented in this paper are those of the writer(s) and do not necessarily reflect the views of the foundations.

\section{Conflicts of Interest}

The authors declare that they have no conflicts of interest to report regarding the present study.

\section{References}

[1] Sulaiman O, Hashim R, Wahab R, Ismail ZA, Samsi HW, Mohamed A. Evaluation of shear strength of oil treated laminated bamboo. Bioresource Technology 2006; 97(18): 2466-2459. https://doi.org/10.1016/j. biortech.2005.10.026.

[2] Harries KA, Bumstead J, Richard M, Trujillo D. Geometric and material effects on bamboo buckling behaviour. Proceedings of the Institution of Civil Engineers-Structures and Buildings 2017; 170(4): 236-249. https://doi.org/10.1680/jstbu.16.00018.

[3] Limin Tian, Yuefeng Kou, Jiping Hao. Axial compressive behaviour of sprayed composite mortar-riginal bamboo composite columns. Construction and Building Materials 2019; 215; 726-736. https://doi.org/ 10.1016/j.conbuildmat.2019.04.234.

[4] Xiao Y, Yang RZ, Shan B. Production, environmental impact and mechanical properties of glubam. Construction and Building Materials 2013; 44: 765-73. https://doi.org/10.1016/j.conbuildmat.2013.03.087.

[5] Wei Yang, Zhao Kunpeng, Hang Chen, Chen Si, Ding Mingmin. Experimental study on the creep behavior of recombinant bamboo. Journal of Renewable Materials 2020; 8(3): 251-273. https://doi.org/ 10.32604/ jrm.2020.08779.

[6] Lv Qingfang, Ding Yi, Liu Ye. Study of the bond behaviour between basalt fibre-reinforced polymer bar / sheet and bamboo engineering materials. Advances in Structural Engineering 2019; 22(14): 3121-3133. https://doi.org/10.1177/1369433219858725.

[7] Yanglun Yu, Ru Liu, Yuxiang Huang, Fandan Meng, Wenji Yu. Preparation, physical, mechanical, and interfacial morphological properties of engineered bamboo scrimber. Construction and Building Materials 2017; 157: 1032-1039. https://doi.org/10.1016/j.conbuildmat.2017.09.185.

[8] Zhong Yong, Ren Haiqing, Jiang Zeihui. Effects of temperature on the compressive strength parallel to the grain of bamboo scrimber. Materials 2016; 9(6): 436. https://doi.org/10.3390/ma9060436.

[9] Haitao Li, Gang Wu, Zhenhua Xiong, Ileana Corbi, Ottavia Corbi, Xiaohong Xiong, Huizhong Zhang, Zhenyu Qiu. Length and orientation direction effect on static bending properties of laminated Moso bamboo. European Journal of Wood and Wood Products 2019; 77(4): 547-557. https://doi.org/10.1007/s00107-01901419-6.

[10] Haitao Li, Rong Liu, Rodolfo Lorenzo, Gang Wu, Libin Wang. Eccentric compression properties of laminated bamboo columns with different slenderness ratios. Proceedings of the Institution of Civil Engineers-Structures and Buildings 2019; 172(5): 315-326. https://doi.org/10.1680/jstbu.18.00007.

[11] Pradhan, NPN, Paraskeva, TS, Dimitrakopoulos, EG. Quasi-static reversed cyclic testing of multi-culm bamboo members with steel connectors. Journal of Building Engineering 2020; 27: 100983. https://doi.org/ 10.1016/j.jobe.2019.100983.

[12] Zhen Wang, Haitao Li, Benhua Fei, Zhenhua Xiong, Rodolfo Lorenzo, Ileana Corbi, Ottavia Corbi, 
Changhua Fang. Axial compressive performance of laminated bamboo column with aramid fiber reinforced polymer. Composites Structures 2021; 258: 113398. https://doi.org/10.1016/j.compstruct.2020.113398.

[13] Qingfang Lv, Weiyang Wang, Ye Liu. Study on Thermal Insulation Performance of Cross-Laminated Bamboo Wall. Journal of Renewable Materials 2019; 7(11): 1231-1250. https://doi.org/10.32604/jrm. 2019.08345.

[14] Han Zhang, Haitao Li, Yanjun Li, Zhenhua Xiong, Nini Zhang, Rodolfo Lorenzo, Mahmud Ashraf. Effect of nodes on mechanical properties and microstructure of laminated bamboo units. Construction and Building Materials 2021; 304: 124427. https://doi.org/10.1016/j.conbuildmat.2021.124427.

[15] Reynolds T, Sharma B, Harries K, Ramage M. Dowelled structural connections in laminated bamboo and timber. Composites Part B: Engineering 2016; 90: 232-240. https://doi.org/10.1016/j.compositesb.2015.11. 045 .

[16] Hang Li, Haitao Li, Chaokun Hong, Zhenhua Xiong, Rodolfo Lorenzo, Ileana Corbi, Ottavia Corbi. Experimental investigation on axial compression behavior of laminated bamboo short columns confined with CFRP. Composites Part A: Applied Science and Manufacturing 2021; 150: 106605. https://doi.org/10.1016/j. compositesa.2021.106605

[17] Verma CS, Chariar VM. Stiffness and strength analysis of four layered laminate bamboo composite at macroscopic scale. Composites Part B: Engineering 2013; 45(1): 369-376. https://doi.org/10.1016/j. compositesb. 2012.07.048.

[18] Chaokun Hong, Haitao Li, Zhenhua Xiong, Rodolfo Lorenzo, Ileana Corbi, Ottavia Corbi. Experimental and numerical study on eccentric compression properties of laminated bamboo column with a chamfered section. Journal of Building Engineering 2021; 43: 102901. https://doi.org/10.1016/j.jobe.2021.102901.

[19] Sinha A, Way D, and Mlasko S. Structural performance of glued laminated bamboo beams. Journal of Structural Engineering 2014; 140(1): 04013021. https://doi.org/10.1061/(ASCE)ST.1943-541X.0000807.

[20] Chaokun Hong, Haitao Li, Zhenhua Xiong, Rodolfo Lorenzo, Xin Li, Zhen Wang. Axial compressive behavior of laminated bamboo columns with a chamfered section. Structures 2021; 33: 678-692. https://doi. org/10.1016/j.istruc.2021.04.083.

[21] Correal JF, Echeverry JS, Fernando Ramírez, Yamín LE. Experimental evaluation of physical and mechanical properties of Glued Laminated Guadua angustifolia Kunth. Construction and Building Materials 2014; 73: 105-112. https://doi.org/10.1016/j.conbuildmat.2014.09.056.

[22] Mahdavi M, Clouston PL, Arwade SR. A low-technology approach toward fabrication of Laminated Bamboo Lumber. Construction and Building Materials 2012; 29: 257-262. https://doi.org/10.1016/j.conbuildmat. 2011. 10.046.

[23] Han Zhang, Haitao Li, Chaokun Hong, Zhenhua Xiong, Rodolfo Lorenzo, Ileana Corbi, Ottavia Corbi. Size effect on the compressive strength of laminated bamboo lumber. Journal of Materials in Civil Engineering ASCE 2021; 33(7): 04021161. https://doi.org/10.1061/(ASCE)MT.1943-5533.0003776.

[24] Xiaofeng Sun, Minjuan He, Zheng Li. Novel engineered wood and bamboo composites for structural applications: state-of-art of manufacturing technology and mechanical performance evaluation. Construction and Building Materials 2020; 249: 118751. https://doi.org/10.1016/j.conbuildmat.2020.118751.

[25] Shan B, Chen CQ, Deng JY, Li TY, Xiao Y. Assessing adhesion and glue-line defects in cold-pressing lamination of glubam. Construction and Building Materials 2021; 274: 122106. https://doi.org/10.1016/j. conbuildmat.2020.122106.

[26] Zhen Wang, Haitao Li, Dong Yang, Zhenhua Xiong, Usama Sayed, Rodolfo Lorenzo, Ileana Corbi, Ottavia Corbi, Chaokun Hong. Bamboo node effect on the tensile properties of side press-laminated bamboo lumber. Wood Science and Technology 2021; 55(1): 195-214. https://doi.org/10.1007/s00226-020-01251-9.

[27] Chen,G, Jiang H, Yu YF, Zhou T, Wu J, Li, X. Experimental analysis of nailed LBL-to-LBL connections loaded parallel to grain. Materials and Structures 2020; 53(4): 1-13. https://doi.org/10.1617/s11527-02001517-5.

[28] Haitao Li, Yiwei Xuan, Bin Xu, Shuheng Li. Bamboo application in civil engineering field. Journal of Forestry Engineering 2020; 5(6): 1-10. https://doi.org/10.13360/j.issn.2096-1359.202003001.

[29] Haitao Li, Xiaoyan Zheng, Nan Guo, Ye Sheng et al. Modern bamboo and timber structures. Beijing: china building industry press, 2020

[30] Standards of China. Load code for the design of building structures (GB50009-2012). Beijing: china building industry press, 2012

[31] Standards of China. Code for seismic design of buildings (GB50011-2010). Beijing: china building industry press, 2021

[32] Standards of China. Code for fire protection design of buildings (GB50016-2014). Beijing: china building industry press, 2006

[33] Standards of China. Standard for design of timber structures (GB 50005-2017). Beijing: china building industry press, 2018 